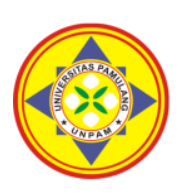

\title{
PENGARUH PELAYANAN TERHADAP KEPUASAN PASIEN POLI GIGI DI RSUD KOTA TANGERANG SELATAN
}

\author{
${ }^{1 *}$ Hastono, ${ }^{2 R}$ Roro Vemmi Kesuma Dewi, ${ }^{3}$ Ika Yulistiana, ${ }^{4}$ Joko Nugroho, \\ 5Rika Febrianti \\ 1Universitas Pamulang, Tangerang Selatan, Banten, Indonesia \\ 2.3.4.5STAI Al Aqidah Al Hasyimiyyah, Jakarta Timur, DKI Jakarta, Indonesia \\ *dosen00340@unpam.ac.id
}

\begin{abstract}
Abstrak
Penelitian ini bertujuan untuk mengetahui pengaruh pelayanan terhadap kepuasan pasien Poli Gigi di RSUD Kota Tangerang Selatan. Metode yang digunakan adalah explanatory research dengan sampel sebanyak 88 responden. Teknik analisis menggunakan analisis statistik dengan pengujian regresi, korelasi, determinasi dan uji hipotesis. Hasil penelitian ini variabel pelayanan diperoleh nilai rata-rata skor sebesar 3,413 dengan kriteria baik. Variabel kepuasan pasien diperoleh nilai rata-rata skor sebesar 3,802 dengan kriteria baik. Pelayanan berpengaruh positif dan signifikan terhadap kepuasan pasien dengan nilai persamaan regresi $Y=10,484+0,807 X$, dan nilai koefisien korelasi 0,750 atau memiliki tingkat hubungan yang kuat dengan nilai determinasi $56,2 \%$. Uji hipotesis diperoleh signifikansi $0,000<0,05$.
\end{abstract}

Kata Kunci: Pelayanan, Kepuasan Pasien.

\section{Abstract}

This study aims to determine the effect of service on patient satisfaction at Dental Polytechnic at RSUD Kota Tangerang Selatan. The method used is explanatory research with a sample of 88 respondents. The analysis technique uses statistical analysis with regression testing, correlation, determination and hypothesis testing. The results of this study the service variable obtained an average score of 3,413 with good criteria. The patient satisfaction variable obtained an average score of 3.802 with good criteria. Service has a positive and significant effect on patient satisfaction with the regression equation $Y=10.484+0.807 X$, and the correlation coefficient value of 0.750 or has a strong level of relationship with a determination value of $56.2 \%$. Hypothesis testing obtained a significance of $0.000<0.05$.

Keywords: Service, Patient Satisfaction.

\section{PENDAHULUAN}

Berkembangnya teknologi dan informasi menyebabkan pengetahuan masyarakat meningkat, sehingga masyarakat lebih selektif dalam memilih layanan yang digunakannya. Salah satu layanan yang penting untuk masyarakat adalah layanan kesehatan gigi, kerena kesehatan gigi dapat mempengaruhi kesehatan tubuh secara menyeluruh. Dengan kata lain bahwa kesehatan gigi merupakan bagian integrasi dari kesehatan tubuh secara keseluruhan yang tidak dapat dipisahkan dari kesehatan tubuh secara umum. Maka dari itu dibutuhkan layanan kesehatan yang optimal agar masyarakat mendapat hasil yang memuaskan.

Menurut Lewis dan Booms dalam Tjiptono (2016:125) Kualitas pelayanan ialah sebagai ukuran seberapa bagus tingkat layanan yang diberikan mampu sesuai dengan ekspektasi pelanggan. Sedangkan menurut Goetsch dan Davis dalam Tjiptono (2016:115) Kualitas ialah sebagai kondisi dinamis yang berhubungan dengan produk, jasa, sumber daya manusia, proses dan lingkungan yang memenuhi atau melebihi harapan pelanggan. Namun menurut kotler keller dalam Tjiptono (2016:125) Kualitas pelayanan harus dimulai dari kebutuhan pelanggan dan 
berakhir dengan kepuasan pelanggan serta persepsi positif terhadap kualitas pelayanan.

Saat ini layanan kesehatan gigi yang diberikan oleh pemerintah, antara lain : Puskesmas dan Rumah Sakit. Didirikannya layanan kesehatan gigi tersebut agar dapat menunjang kesehatan masyarakat secara luas, baik yang mampu maupun kurang mampu. Dengan didirikannya fasilitas layanan kesehatan oleh pemerintah diharapkan dapat meningkatkan kesejahteraan dan taraf hidup masyarakat. Salah satu layanan kesehatan yang penting adalah Rumah Sakit.

Rumah Sakit adalah salah satu organisasi sektor publik yang bergerak dalam bidang pelayanan jasa kesehatan yang mempunyai tugas melaksanakan suatu upaya kesehatan secara berdaya guna dan berhasil guna dengan mengutamakan atau yang telah dilaksanakan secara serasi dan terpadu oleh pihak Rumah Sakit dalam upaya peningkatan dan pencegahan penyakit serta upaya perbaikan (Keputusan Menteri Kesehatan Republik Indonesia No.983/Men.Kes/SK/XI/1992).

Rumah Sakit tidak hanya sekedar menampung orang sakit saja melainkan harus lebih memerhatikan aspek kepuasan bagi para pemakai jasanya. Menurut Kotler dan Keller (2009:138) Kepuasan pelanggan adalah perasaan senang atau kecewa seseorang yang timbul karena membandingkan kinerja yang dipersepsikan produk (hasil) terhadap ekspektasi mereka. Sedangkan menurut Zeithaml dan Bitner dalam Jasfar (2012:19) Kepuasan pelanggan adalah perbandingan antara persepsi pelanggan tehadap jasa yang diterima dan harapannya sebelum menggunakan jasa tersebut, Menurut Tjiptono (2016:204) Kepuasan bisa diartikan sebagai upaya pemenuhan sesuatu atau membuat sesuatu memadai.

Penilaian terhadap kegiatan Rumah Sakit adalah hal yang sangat diperlukan dan sangat diutamakan. Kegiatan penilaian kinerja organisasi atau instansi seperti Rumah Sakit mempunyai banyak manfaat terutama bagi pihak-pihak yang memiliki kepentingan terhadap Rumah Sakit tersebut. Bagi pemilik Rumah Sakit, hasil penilaian kegiatan Rumah Sakit ini dapat memberikan informasi tentang kinerja manajemen atau pengelola. Bagi masyarakat, semua hasil penilaian kinerja Rumah Sakit dapat dijadikan sebagai acuan atau bahan pertimbangan kepada siapa (Rumah Sakit) mereka akan mempercayakan perawatan kesehatan giginya.

\section{TINJAUAN PUSTAKA}

1. Pelayanan

Menurut Tjiptono (2017:59) menyatakan bahwa "Kualitas pelayanan adalah tingkat keunggulan yang diharapkan dan pengendalian atas tingkat keunggulan tersebut untuk memenuhi keinginan pelanggan". Definisi lain kualitas pelayanan menurut Wyckof dalam Lovelock yang dikutip oleh Tjiptono (2017:270) merupakan tingkat keunggulan (excellence) yang diharapkan dan pengendalian atas keunggulan tersebut untuk memenuhi keinginan pelanggan. Sedangkan menurut Parasuraman dalam Lupiyoadi (2017:216) bahwa "kualitas pelayanan yaitu seberapa jauh perbedaan antara kenyataan dan harapan pelanggan atas pelayanan yang mereka terima".

2. Kepuasan Pasien

Dari seluruh proses kegiatan pemberian produk maupun jasa kepada pelanggan oleh sebuah perusahaan, pada akhirnya akan bermuara pada nilai yang akan diberikan oleh pelanggan mengenai kepuasan yang dirasakan. Pentingnya kepuasan pelanggan berkaitan dengan persaingan yang makin ketat, serta tingkat kerugian dan keuntungan perusahaan. Menurut Yazid (2016:55) berpendapat "Kepuasan pelanggan adalah ketiadaan perbedaan antara harapan yang dimiliki dan unjuk kerja yang senyatanya diterima. Apabila harapan tinggi, sementara unjuk kerjanya biasa-biasa saja, kepuasan tidak akan tercapai (sangat mungkin pelanggan akan merasa kecewa. 
Sebaliknya, apabila unjukkerja melebihi dari yang diharapkan, kepuasan meningkat".

\section{METODE}

Populasi dalam penelitian ini berjumlah 88 responden Pasien RSUD Kota Tangeran Selatan. Teknik pengambilan sampling dalam penelitian ini adalah sampel jenuh, dimana semua anggota populasi dijadikan sebagai sampel. Dengan demikian sampel dalam penelitian ini sampel yang digunakan berjumlah 88 responden.

Jenis penelitian yang dipakai adalah asosiatif, dimana tujuannya adalah untuk mengetahui atau mencari keterhubungan antara variabel independen terhadap variabel dependennya. Dalam menganalisis data digunakan uji validitas, uji reliabilitas, analisis regresi linier sederhana, analisis koefisien korelasi, analisis koefisien determinasi dan pengujian hipotesis.

\section{HASIL DAN PEMBAHASAN}

\section{Analisis Deskriptif}

Pada pengujian ini digunakan untuk mengetahui skor minimum dan maksimum skor tertinggi, ratting score dan standar deviasi dari masing-masing variabel. Adapun hasilnya sebagai berikut:

Tabel 1. Hasil Analisis Descriptive Statistics

Descriptive Statistics

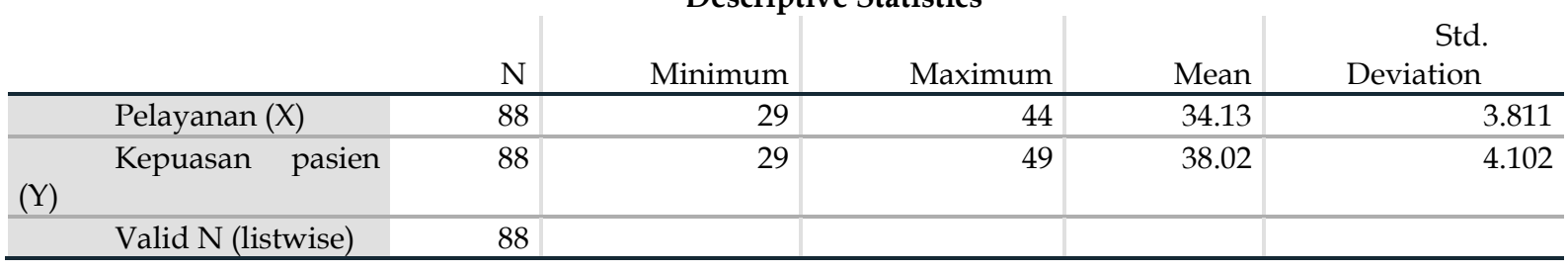

Pelayanan diperoleh varians minimum sebesar 29 dan varians maximum 44 dengan ratting score sebesar 3,413 dengan standar deviasi 3,811 . Skor ini termasuk pada rentang sakala 3,40 - 4,19 dengan kriteria baik atau setuju.

Kepuasan pasien diperoleh varians minimum sebesar 29 dan varians maximum 49 dengan ratting score sebesar 3,802 dengan standar deviasi 4,102. Skor ini termasuk pada rentang sakala 3,40 - 4,19 dengan kriteria baik atau setuju.

\section{Analisis Verifikatif.}

Pada analisis ini dimaksudkan untuk mengetahui pengaruh variabel independen terhadap variabel dependen. Adapun hasil pengujian sebagai berikut:

a. Analisis Regresi Linier Sederhana

Uji regresi ini dimaksudkan untuk mengetahui perubahan variabel dependen jika variabel independen mengalami perubahan. Adapun hasil pengujiannya sebagai berikut:

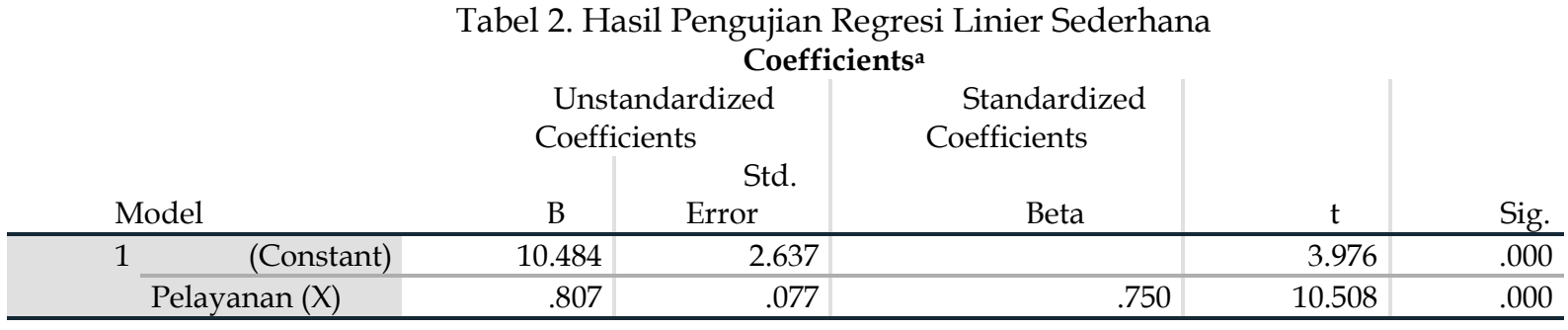

Berdasarkan hasil pengujian
pada tabel di atas, diperoleh
persamaan regresi $\mathrm{Y}=10,484+$
0,807X. Dari persamaan tersebut
dijelaskan sebagai berikut:

Berdasarkan hasil pengujian persamaan regresi $\mathrm{Y}=10,484+$ 0,807X. Dari persamaan tersebut dijelaskan sebagai berikut:
1) Konstanta sebesar 10,484 diartikan jika pelayanan tidak ada, maka telah terdapat nilai kepuasan pasien sebesar 10,484 point. 
2) Koefisien regresi pelayanan sebesar 0,807, angka ini positif artinya setiap ada peningkatan pelayanan sebesar 0,807 point maka kepuasan pasien juga akan mengalami peningkatan sebesar 0,807 point. b. Analisis Koefisien Korelasi

Analisis koefisien korelasi dimaksudkan untuk mengetahui tingkat kekuatan hubungan dari variabel independen terhadap variabel dependen. Adapun hasil pengujian sebagai berikut:

Tabel 3. Hasil Pengujian Koefisien Korelasi Pelayanan Terhadap Kepuasan pasien. Correlations $^{b}$

\begin{tabular}{llrr} 
& & Pelayanan $(\mathrm{X} 1)$ & Kepuasan pasien $(\mathrm{Y})$ \\
\hline Pelayanan $(\mathrm{X})$ & Pearson Correlation & 1 & $.750^{* *}$ \\
\cline { 2 - 4 } & Sig. (2-tailed) & & .000 \\
\hline Kepuasan pasien $(Y)$ & Pearson Correlation & $.750^{* *}$ & 1 \\
\cline { 2 - 4 } & Sig. (2-tailed) & .000 & \\
\cline { 2 - 4 }
\end{tabular}

Berdasarkan hasil pengujian diperoleh nilai korelasi sebesar 0,750 artinya pelayanan memiliki hubungan yang kuat terhadap kepuasan pasien. c. Analisis Koefisien Determinasi

Analisis koefisien determinasi dimaksudkan untuk mengetahui besarnya persentase pengaruh dari variabel independen terhadap variabel dependen. Adapun hasil pengujian sebagai berikut:

Tabel 4. Hasil Pengujian Koefisien Determinasi Pelayanan Terhadap Kepuasan pasien.

\begin{tabular}{lrr|r|r} 
& & \multicolumn{2}{c}{ Model Summary } & Std. Error of the Estimate \\
\hline 1 & $\mathrm{R}$ & R Square & Adjusted R Square & 2.730 \\
\hline
\end{tabular}

Berdasarkan hasil pengujian diperoleh nilai determinasi sebesar 0,562 artinya pelayanan memiliki kontribusi pengaruh sebesar $56,2 \%$ terhadap kepuasan pasien, sedangkan sisanya sebesar $43,8 \%$ dipengaruhi oleh faktor lain yang tidak dilakukan penelitian. d. Uji Hipotesis

Pengujian hipotesis dengan uji $\mathrm{t}$ digunakan untuk mengetahui hipotesis mana yang diterima.

Rumusan hipotesis: Terdapat pengaruh yang signifikan antara pelayanan terhadap kepuasan pasien.

Tabel 5. Hasil Uji Hipotesis Pelayanan Terhadap Kepuasan pasien.

\begin{tabular}{|c|c|c|c|c|c|}
\hline \multirow[b]{3}{*}{ Model } & \multicolumn{3}{|c|}{ Coefficientsa } & \multirow[b]{3}{*}{$\mathrm{t}$} & \multirow[b]{3}{*}{ Sig. } \\
\hline & \multicolumn{2}{|c|}{$\begin{array}{l}\text { Unstandardized } \\
\text { Coefficients }\end{array}$} & \multirow{2}{*}{$\begin{array}{c}\text { Standardized } \\
\text { Coefficients } \\
\text { Beta }\end{array}$} & & \\
\hline & B & $\begin{array}{l}\text { Std. } \\
\text { Error }\end{array}$ & & & \\
\hline (Constant) & 10.484 & 2.637 & & 3.976 & .000 \\
\hline Pelayanan $(X)$ & .807 & .077 & .750 & 10.508 & .000 \\
\hline
\end{tabular}

\section{PEMBAHASAN HASIL PENELITIAN}

1. Kondisi Jawaban Responden Variabel Pelayanan

Berdasarkan jawaban responden, variabel pelayanan diperoleh ratting score sebesar 3,413 berada di rentang skala 3,40 - 4,19 dengan kriteria baik atau setuju.
2. Kondisi Jawaban Responden Variabel Kepuasan pasien

Berdasarkan jawaban responden, variabel kepuasan pasien diperoleh ratting score sebesar 3,802 berada di rentang skala 3,40 - 4,19 dengan kriteria baik atau setuju.

3. Pengaruh Pelayanan Terhadap Kepuasan pasien 
Pelayanan berpengaruh signifikan terhadap kepuasan pasien dengan persamaan regresi $\mathrm{Y}=10,484+0,807 \mathrm{X}$, nilai korelasi sebesar 0,750 atau memiliki hubungan yang kuat dengan kontribusi pengaruh sebesar 56,2\%. Pengujian hipotesis diperoleh nilai thitung $>\mathrm{t}$ tabel atau $(10,508>1,988)$. Dengan demikian hipotesis yang diajukan bahwa terdapat berpengaruh signifikan antara pelayanan terhadap kepuasan pasien diterima.

\section{PENUTUP}

\section{Kesimpulan}

1. Variabel pelayanan diperoleh ratting score sebesar 3,413 berada di rentang skala 3,40 - 4,19 dengan kriteria baik atau setuju.

2. Variabel kepuasan pasien diperoleh ratting score sebesar 3,802 berada di rentang skala 3,40 - 4,19 dengan kriteria baik atau setuju.

3. Pelayanan berpengaruh signifikan terhadap kepuasan pasien dengan persamaan regresi $\mathrm{Y}=10,484+0,807 \mathrm{X}$, nilai korelasi sebesar 0,750 atau kuat dan kontribusi pengaruh sebesar 56,2\% sedangkan sisanya sebesar 43,8\% dipengaruhi faktor lain. Uji hipotesis diperoleh nilai $\mathrm{t}$ hitung $>\mathrm{t}$ tabel atau $(10,508>1,988)$.

\section{Saran}

1. Untuk meningkatkan kualitas pelayanan poli gigi sebaiknya pihak RSUD Kota Tangerang Selatan harus lebih memperhatikan proses penerimaan pasien pada bagian administrasi agar proses penerimanaan pasien dapat berjalan dengan cepat dan lancar.

2. Masih terdapat pasien poli gigi yang mengeluhkan tentang obat yang diberikan RSUD Kota Tangerang Selatan sehingga pihak RSUD harus lebih meningkatkan kualitas obat yang diberikan kepada pasien poli gigi agar pasien tidak merasa sakit lagi

3. ika dilihat dari itngkat hubungan bahwa kualitas pelayanan poli gigi yang diberikan oleh RSUD Kota Tangerang
Selatan memiliki hubungan yang sedang, sekalipun ada pengaruhnya terhadap kepuasan pasien poli gigi, namun alangkan lebih baiknya jika kualitas pelayanan poli gigi yang diberikan lebih ditingkatkan lagi agar dapat memberikan feed back yang baik bagi RSUD maupun pasien poli gigi yang berobat di RSUD Kota Tangerang Selatan.

\section{DAFTAR PUSTAKA}

Algifari. (2015). "Analisis Regresi untuk Bisnis dan Ekonomi". Yogyakarta: BPFE.

Arikunto, Suharsimi (2014). "Prosedur Penelitian Suatu Pendekatan Praktek". Jakarta: Rineka Cipta.

Ariyanto, A., Nuryani, A., \& Sunarsi, D. (2020). Pengaruh Store Atmosphere Dan Promosi Terhadap Keputusan Pembelian Pada Alfamart BSD Tangerang Selatan. Jurnal Ekonomi Efektif, 3(1).

Bashu Swastha dan T. Handoko (2015) Manajemen Pemasaran Moderen, Yogyakarta: BPFE.

Basu Swastha Dharmmesta. (2014). Manajemen Pemasaran. BPFE: Yogyakarta. Buchari Alma. 2014. Manajemen pemasaran dan Pemasaran Jasa. Edisi Revisi.

Bilson Simamora (2016) Panduan Riset Prilaku Konsumen, Jakarta: PT. Gramedia Pustaka.

Fandy Tjiptono (2017), Serivce Quality and Satisfiation. Jakarta: Edisi tiga. Andi.

Freddy Rangkuti (2016) Strategi Promosi Yang Kreatif, Edisi Pertama, Cetakan Pertama Jakarta: Gramedia Pustaka Utama.

Haque, MG., Munawaroh, Sunarsi, D., (2020). Analysis of SMEs Culinary Marketing Strategy During Covid 19 Pancemic: A Study at "Sate Bebek Cilegon" Resto in Cilegon, Banten. International Journal of Education, Information Technology, and Others. Vol.3. Issue 2

Imam Ghozali (2017). "Aplikasi Analisis Multivariate Dengan Program SPSS". 
Edisi Kelima. Semarang: Badan Penerbit Undip.

Irmal, I., Gustiarani, E., \& Sunarsi, D. (2020). Pengaruh E-Marketing dan E-CRM terhadap E-Loyalty Pengunjung Situs Website www. Cangkirbogor. com. Jurnal Ekonomi Efektif, 2(2).

Istijanto (2014) "Riset Sumber Daya Manusia". Jakarta: PT. Gramedia Pustaka

Jasmani, J. (2018). Pengaruh Kualitas Produk Dan Harga Terhadap Keputusan Pembelian Pada PT. Baja Mandiri Di Jakarta. Disrupsi Binis, $1(1)$.

. (2019). The Effect of Leadership and Competence on Lecturer Performance and Its Implications on Student Learning Motivation at Pamulang University. International Journal of Advances in Social and Economics, 1(4).

(2020). Analysis of the Effect of Prices, Promotions and Products on Purchase Interest Impacts on Consumer Satisfaction of VIVO Brand Mobile Phones in South Tangerang Region. Jurnal Ad'ministrare, 7(1), 7382.

Kasmad, K., Mustakim, M., \& Sunarsi, D. (2020). Increasing Community School Interest Through Service Quality, Prices and Promotion in Vocational High Schools. Journal of Educational Science and Technology (EST), 6(2).

Kharis, Ismu Fadli (2011). "Studi Mengenai Impulse Buying dalam Penjualan Online". Semarang : Skripsi Universitas Diponegoro

Kotler dan Amstrong (2017), Prinsip-prinsip Pemasaran. Edisi Kedua Belas". Jilid Satu. Jakarta: Erlangga.

Lupiyoadi (2016) Manajemen Pemasaran Jasa, Edisi 4, Jakarta: Salemba Empat.
Maddinsyah, A., Hidayat, D., Juhaeri, J., Susanto, D., \& Sunarsi, D. (2020). Desain Formulasi Dan Implementasi Bisnis Strategik Dengan Pendekatan Business Model Canvas (BMC) Terintegrasi Kerangka Integrated Performance Management System (IPMS) Pada Koperasi Asperindo. Inovasi, 7(2), 67-76.

Mani, J. (2017). Pengaruh Persepsi Merek Dan Kualitas Pelayanan Terhadap Kepuasan Konsumen (Studi Kasus Pada PT. Bisma Narendra Di Jakarta). Jurnal Mandiri, 1(2), 187-206.

Philip Kotler (2017) Manajemen Pemasaran, Edisi Keempat Belas, Jakarta: PT. Indeks.

Phipil Kotler dan Kevin Keller (2017) Manajemen Pemasaran, Edisi Kedua Belas, Jilid Satu, Jakarta: Erlangga.

Rao, Purba, (2012). "Measuring Consumer Perceptions Through Factor Analysis", The Asian.

Santoso, Singgih (2015). "Menguasai Statistik Multivariat". Jakarta: PT Elex Media Komputindo.

Sudjana (2014) "Metode Statistika", Bandung: Tarsido.

Sugiyono (2017), "Metode Penelitian Administrasi : dilengkapi dengan Metode R \& D". Bandung: Alfabeta.

Suhartanto (2014). "Metode Riset Pemasaran". Bandung: Alfabeta

Sunarsi, D. (2020). Pengaruh Bauran Pemasaran Dan Kualitas Pelayanan Terhadap Kepuasan Konsumen Pada Giant Dept Store Cabang BSD Tangerang. E-Mabis: Jurnal Ekonomi Manajemen dan Bisnis, 21(1).

Y Kadarusman, D Sunarsi. (2020). Pengaruh Strategi Penetapan Harga Terhadap Peningkatan Jumlah Siswa Pada SMK PGRI Balaraja. JS (JURNAL SEKOLAH) 4 (3), 213-221. 